4. Сафроненкова И. А. Состояние иммунной системы больных злокачественными эпителиальными опухолями век / И. А. Сафроненкова // Офтальмол. журн. - 2012. - № 1. - С.39-41.

5. Хлебникова А. Н. Гистологические варианты базальноклеточного рака кожи / Хлебникова А. Н., Казанцева И. А. // Рос. журн. кожн. и венерич. бол. 2000. - № 2. - С. 4-6.

6. Шенталь В. В. Рак кожи / Шенталь В. В., Пустынский И. Н., Малаев С. Г. // Мед помощь. - 2000. № 4. - C.6-10.

7. Devis D. Phototoxicity: environmental hazard and therapeutic tool / Devis D., Marvin W. // Drug Topics. 2001. - V.145. - № 14. - P. 41-51.
8. Incidence Estimate of Nonmelanoma Skin Cancer in the United States, 2006 / Rogers H. W., Weinstock M. A., Harris A. R. [et al] // Arch. Dermatol. - 2010. - V.146. № 3. - P. 283-287.

9. Need for a New Skin Cancer Management Strategy / van der Geer S., Reijers H. A., van Tuijl H. F. J. M, [et al.] // Arch. Dermatol. - 2010. - V.146. - № 3. P.332-336.

10. Stern R. S. Prevalence of a History of Skin Cancer in 2007 / Stern R. S. // Arch. Dermatol. - 2010. - V.146. № 3. - P.279-282.

Поступила 20.06.2012 Рецензент д. М. н. С. И. Полякова

\title{
THE EXPRESSION LEVEL OF ANTIGENS CD16+, CS25+ AND CD95+ BY LYMPHOCYTES OF THE PERIPHERAL BLOOD IN PATIENTS WITH MALIGNANT EPITHELIAL TUMOURS OF THE EYELIDS DURING COMBINED TREATMENT \\ Safronenkova I. A. \\ Odessa, Ukraine
}

There was studied the expressional level of subpopulation of CD16+, CD25+, CD95+ lymphocytes in 165 patients with malignant epithelial tumors (MET) of the skin of the eyelids and in 28 conditionally healthy persons using the same monoclonal antibodies. It has been established the significant increasing of antigens CD25+ and CD95+ expression and decreasing of CD16+ expression of MET of skin of eyelid in comparison with normal. It testifies to the decreasing of antitumor immunity in patients with MET of the skin of the eyelids and to acquisition of ability of immune system to stimulation of growth of tumoral cells. Significantly The significant decreasing of CD25+ and CD95+ expression in 6 and 12 months after combined treatment (radiotherapy + cryodestruction) testifies to the beginning of restoration of immunity in patients with MET of the eyelids scin.

УДК 617.723-006.81.04-097-092.8-085.849.19

\section{ОСОБЕННОСТИ ВЗАИМОДЕЙСТВИЯ КЛЕТОК МЕЛАНОМЫ С МАКРОФАГАМИ ПЕРИФЕРИЧЕСКОЙ КРОВИ У БОЛЬНЫХ МЕЛАНОМОЙ ГЛАЗА ПРИ РАЗЛИЧНОМ КЛИНИЧЕСКОМ ТЕЧЕНИИ ОПУХОЛЕВОГО ПРОЦЕССА}

\author{
Л. Н. Величко, к. М. Н., В. В. Вит, д. м. Н., проф.
}

ГУ «Институт глазных болезней и тканевой терапии им. В. П. Филатова НАМН Украины»

\begin{abstract}
Вивчено особливості взаємодії меланомних клітин з макрофагами периферичної крові у 22 хворих на увеальну меланому. Проводилось вивчення макрофаг-пухлинного розеткоутворення та ступеня цитотоксичного пошкодження пухлинних клітин макрофагами у хворих з різною ефективністю лікування. У хворих на увеальну меланому з метастазами встановлено достовірне підвищення рівня макрофаг-пухлинного розеткоутворення, а також відсутність цитотоксичного пошкодження пухлинних клітин макрофагами, порівняно з групою хворих з прогресивним зменшенням пухлини. Регресія меланоми супроводжується цитотоксичним ушкодженням пухлинних клітин.
\end{abstract}

Ключевые слова: увеальная меланома, опухолевые клетки, макрофаги, метастазирование

Ключові слова: увеальна меланома, пухлинні клітини, макрофаги, метастазування

Введение. Изучение значения микрометастазов является одной из важных проблем онкологии. Но уже сегодня можно говорить о том, что наличие опухолевых клеток в крови в большинстве случаев определяет неблагоприятный прогноз [5].
Однако подобное мнение не является окончательным, так как большинство одиночных метастатических клеток-эмболов не дают начало развитию истинных метастазов. Остается неясной природа

(с) Л. Н. Величко, В. В. Вит, 2012 
взаимоотношений этих изолированных опухолевых клеток с другими факторами, определяющими процессы рецидивирования или метастазирования.

Получены убедительные доказательства усиления роста опухоли in vivo и деления опухолевых клеток в культуре под влиянием макрофагов. Существует мнение, что «приходящие» в опухоль моноциты под влиянием специфического опухолевого микроокружения дифференцируются в макрофаги, способствующие росту и поддержанию гомеостаза опухолевой ткани [3]. Другими исследованиями показано, что зрелые опухолеассоциированные макрофаги экспрессируют антиген 25 F-9. Присутствие в опухоли макрофагов с таким фенотипом сопряжено с усилением ее роста и метастазирования [4]. Таким образом, существуют какие-то специфические механизмы, факторы, благодаря которым злокачественные клетки, взаимодействуя с определенными субпопуляциями иммунокомпетентных клеток и отдельными медиаторами иммунной системы, в частности фактором некроза опухолей интерлейкином 4, могут стимулировать развитие метастатического процесса [4].

При метастазировании опухолей происходят существенные перестройки в микроокружении опухоли, изменяются процессы межклеточной кооперации. Познание механизмов взаимодействия опухолевых и иммунокомпетентных клеток будет способствовать выработке путей целенаправленного воздействия на метастатический процесс. Недостаточно изучены межклеточные взаимодействия в системе (опухоль - иммунная система) при различном типе реакции опухоли на проводимое лечение у больных меланомой глаза.

Целью настоящего исследования явилось изучение особенностей взаимодействия опухолевых клеток меланомы с макрофагами периферической крови у больных меланомой глаза при различном клиническом течении опухолевого процесса.

МАТЕРИАЛ И МЕТОДЫ. Все пациенты (22 человека) разделены на три группы. Первая группа состояла из больных увеальной меланомой, у которых в процессе органосохранного лечения (фотокоагуляция $+\beta$ аппликационная терапия) отмечена регрессия опухоли (10 человек). Во вторую группу вошли больные увеальной меланомой, у которых в процессе органосохранного лечения отмечен продолженный рост опухоли (5 человек). Третью группу составили больные меланомой глаза, у которых были выявлены метастазы (7 человек). Из них у 4 пациентов увеальной меланомой были выявлены метастазы в печени. У двоих пациентов с меланомой конъюнктивы метастазы обнаружены в околоушных и подчелюстных лимфатических узлах. У одного пациента с меланомой орбиты метастазы выявлены в пазухах носа.

Венозную кровь исследуемых больных помещали во флакон с полной культуральной средой с добавлением 20ED гепарина и хепес-буфера, на дно флакона помещали покровное стекло. Через 24 часа после адгезии моноцитов к стеклу и их трансформации в макрофаги, стекло промы- вали в среде 199, после чего помещали во флакон с полной культуральной средой и добавляли меланомные клетки в количестве $5,2 \times 10^{9}$ кл (краткосрочные суспензионные культуры меланомных клеток, полученные из фрагментов опухоли после проведения энуклеации глазного яблока по поводу увеальной меланомы больших размеров). Дезагрегацию опухоли проводили путем встряхивания кусочка опухоли, находившегося в полной культуральной среде, с последующим сбором отделившихся опухолевых клеток. Изучение функциональных характеристик клеток исключало возможность использования каких-либо биологически активных веществ, в том числе протеаз.

Совместное культивирование опухолевых клеток с макрофагами проводили в течение 24 часов при $\mathrm{t} 37^{\circ} \mathrm{C}$. После окончания срока культивирования, стекло извлекали, фиксировали $80^{\circ}$ спиртом, окрашивали азур-эозином, микроскопирование проводили с применением объектива $\mathbf{4 0}$ окуляра х10. При микроскопировании проводили подсчет: (1) процентного содержания макрофаг-опухолевых розеток на 100 опухолевых клеток; (2) процентного содержания опухолевых клеток с признаками цитотоксического повреждения на 100 опухолевых клеток.

Статистическую обработку проводили методами непараметрической статистики (ANOVA с использованием рангового критерия Краскела-Уоллиса, использовался также критерий сопряженности Пирсона).

РЕЗУЛЬТАТЫ ИССЛЕДОВАНИЙ И ИХ ОБСУЖДЕНИЕ. Сравнительный анализ образования макрофаг-опухолевых розеток проводили в зависимости от клинического течения опухолевого процесса (табл. 1).

Таблица 1

Уровень макрофаг-опухолевого розеткообразования у больных увеальной меланомой при различном клиническом течении опухолевого процесса

\begin{tabular}{|c|c|c|c|c|c|c|}
\hline \multirow{2}{*}{$\begin{array}{l}\text { Иссле- } \\
\text { дуемые } \\
\text { группы } \\
\text { больных }\end{array}$} & \multirow{2}{*}{$\begin{array}{c}\text { Клини- } \\
\text { ческое } \\
\text { течение } \\
\text { опухоли }\end{array}$} & \multicolumn{3}{|c|}{$\begin{array}{c}\text { Уровень макрофаг- } \\
\text { опухолевого розеткоо- } \\
\text { бразования, \% }\end{array}$} & \multirow{2}{*}{$\begin{array}{c}\text { Стан- } \\
\text { дарт- } \\
\text { ное } \\
\text { откло- } \\
\text { нение } \\
\text { SD } \\
\end{array}$} & \multirow[b]{2}{*}{ p } \\
\hline & & $\begin{array}{c}\text { Сред- } \\
\text { нее } \\
\text { М } \\
\end{array}$ & $\begin{array}{c}\text { Ми- } \\
\text { нимум } \\
\text { min } \\
\end{array}$ & $\begin{array}{c}\text { Мак- } \\
\text { симум } \\
\max \\
\end{array}$ & & \\
\hline 1 & $\begin{array}{c}\text { Регрес- } \\
\text { сия } \\
\mathrm{n}=10\end{array}$ & 3,6 & 3,0 & 5,0 & $\pm 0,7$ & $\begin{array}{c}\mathrm{p}_{1-2}= \\
0,00016\end{array}$ \\
\hline 2 & $\begin{array}{c}\text { Про- } \\
\text { грессия } \\
\mathrm{n}=5\end{array}$ & 7,2 & 6,0 & 8,0 & $\pm 0,8$ & $\begin{array}{c}\mathrm{p}_{1-3}= \\
0,00014\end{array}$ \\
\hline 3 & $\begin{array}{c}\text { Мета- } \\
\text { стазы } \\
\mathrm{n}=7\end{array}$ & 11,6 & 10,0 & 13,0 & $\pm 0,98$ & $\begin{array}{c}\mathrm{p}_{2-3}= \\
0,00016\end{array}$ \\
\hline
\end{tabular}

Примечание: $\mathrm{n}$ - количество больных, $\mathrm{p}-$ уровень значимости различий по ранговому критерию Краскела-Уоллиса.

При регрессии увеальной меланомы среднее значение образования макрофаг-опухолевых розеток было наиболее низким и составило $(3,6 \% \pm 0,7) \%$.

У больных с прогрессивным ростом увеальной меланомы среднее значение макрофаг-опухолевого розеткообразования было значительно выше, чем у больных с регрессией опухоли и составило $(7,2 \% \pm 0,8) \%\left(p_{1-2}=0,00016\right)$. 
Таблица 2

Распределение больных с различным характером течения меланомы глаза в зависимости от процентного содержания опухолевых клеток с признаками цитотоксического повреждения после их совместного культивирования с макрофагами периферической крови

\begin{tabular}{|c|c|c|c|c|c|c|}
\hline \multirow[t]{2}{*}{$\begin{array}{l}\text { Иссле- } \\
\text { дуемые } \\
\text { группы } \\
\text { больных }\end{array}$} & \multirow[t]{2}{*}{$\begin{array}{c}\text { Клиническое } \\
\text { течение опу- } \\
\text { холи }\end{array}$} & \multicolumn{4}{|c|}{$\begin{array}{c}\text { Процентное содержание } \\
\text { опухолевых клеток с при- } \\
\text { знаками цитотоксического } \\
\text { повреждения }\end{array}$} & \multirow{2}{*}{$\begin{array}{c}\text { Всего } \\
\text { боль- } \\
\text { ных }\end{array}$} \\
\hline & & $0 \%$ & $1 \%$ & $3 \%$ & $4 \%$ & \\
\hline 1 & Регрессия & 0 & 0 & 8 & 2 & 10 \\
\hline 2 & Прогрессия & 2 & 3 & 0 & 0 & 5 \\
\hline 3 & Метастазы & 5 & 2 & 0 & 0 & 7 \\
\hline \multicolumn{2}{|c|}{ Всего больных } & 7 & 5 & 8 & 2 & 22 \\
\hline
\end{tabular}

Примечание: в представленной таблице сопряженность признаков цитотоксического повреждения опухолевых клеток с характером течения опухолевого процесса достоверна $\chi^{2}=24,2$ $(\mathrm{p}=0,0049)$.

В группе больных с метастазами меланомы среднее значение макрофаг-опухолевого розеткообразования было наиболее высоким и составило $11,6 \% \pm 0,93 \%\left(\mathrm{p}_{1-3}=0,00014 ; \mathrm{p}_{2-3}=0,00016\right)$.

Следует также отметить, что у больных увеальной меланомой с метастазами в печень процент макрофаг-опухолевого розеткообразования был ниже, чем у больных с меланомой конъюнктивы с метастазами в околоушные и подчелюстные лимфатические узлы и меланомой орбиты, метастазировавшей в пазухи носа. Данные показатели не были достоверными по уровню значимости различий.

Нами также был проведен анализ процентного содержания опухолевых клеток с признаками цитотоксического повреждения после их совместного культивирования с макрофагами периферической крови больных меланомой глаза с различным характером течения опухолевого процесса (табл. 2).

При регрессии увеальной меланомы в процессе органосохранного лечения доля опухолевых клеток с признаками цитотоксического повреждения после их совместного культивирования с макрофагами в 8 случаях составила $3 \%$, а у двоих больных $4 \%$, что свидетельствует о высокой цитотоксической активности макрофагов.

У больных с прогрессивным ростом увеальной меланомы в процессе органосохранного лечения в двух случаях опухолевые клетки не имели признаков цитотоксического повреждения после культивирования с макрофагами, в трёх случаях количество поврежденных клеток составило $1 \%$, что свидетельствует о снижении цитотоксической активности макрофагов.

У 5 больных меланомой (4 больных с увеальной меланомой с метастазами в печень и 1 больной меланомой орбиты с метастазами в пазухи носа) опухолевые клетки не имели признаков цитотоксического повреждения после их совместного культи- вирования с макрофагами периферической крови, что свидетельствует о полной деактивации функций макрофагов. У 2 больных с меланомой конъюнктивы с метастазами в околоушные и подчелюстные лимфатические узлы уровень цитотоксического повреждения опухолевых клеток не превышал $1 \%$, свидетельствуя о выраженном ослаблении противоопухолевой защиты.

Таким образом, полученные нами результаты показали, что эффективность противоопухолевого иммунитета снижается при прогрессивном росте опухоли и ее метастазировании. Несмотря на увеличение уровня макрофаг-опухолевого розеткообразования у больных с прогрессивным ростом и метастазированием степень цитотоксического повреждения опухолевых клеток снижается.

Способность мононуклеарных фагоцитов лизировать опухолевые мишени известна давно. Мононуклеарные фагоциты, подобно другим клеткам системы иммунитета, могут оказывать как негативное, так и позитивное действие на рост опухоли [1].

В высшей степени интересным и важным представляется вопрос о том, каким образом биологические особенности опухолевых клеток влияют на макрофаги.

Опухолевые клетки при их взаимодействии с макрофагами могут по-разному влиять на функции последних благодаря выделению различных молекул с регуляторной активностью.

В плане обсуждения полученных результатов необходимо отметить, что под действием TGF- $\beta 1$, секретируемого опухолевыми клетками, снижаются активация и фагоцитоз инфильтрирующих опухоль макрофагов и происходит их трансформация в фенотип М2, который ассоциирован с функциональным состоянием клеток, ориентированным на поддержание роста опухоли [2].

Согласно данным других исследователей, у макрофагов фенотипа М2 наблюдается и увеличенная экспрессия протеолитических ферментов - металлопротеиназ, разрушающих внеклеточный матрикс, и фактора роста эндотелия сосудов (VEGF), активирующего ангиогенез и являющегося одним из факторов опухолевой иммуносупрессии [6].

Соотношение среди клеток опухолевой стромы макрофагов фенотипа М1 (конвенционные макрофаги с преимущественно противоопухолевым действием) и М2 зависит от продолжительности существования опухоли и ряда других факторов.

По мнению Tsai N. M., Chen B. M., Wei S. L. et al, итогом первой фазы иммунного ответа на опухоль является уничтожение большинства опухолевых клеток с сохранением части опухолевых клеток, приобретающих способность в той или иной степени контролировать развитие иммунного ответа. Со- 
вместное воздействие TGF- $\beta 1$ и VEGF инициирует формирование опухолевой стромы, необходимой для обеспечения трофики опухолевых клеток, иммуносупрессивного действия и поддержания процесса метастазирования [7].

Заключение. При регрессии увеальной меланомы опухолевые клетки после контакта с макрофагами имели многочисленные разрывы цитоплазматической оболочки с признаками деструкции, что свидетельствует о высокой цитотоксической активности макрофагов.

При прогрессивном росте увеальной меланомы отмечено выраженное ослабление противоопухолевой защиты, выражающееся в резком снижении цитотоксической активности макрофагов. У больных увеальной меланомой с метастазами в печень происходит деактивация макрофагов. Высокий уровень образования макрофаг-опухолевых розеток не сопровождается цитотоксическим повреждением опухолевых клеток макрофагами. Данный вид взаимодействия опухолевых клеток с макрофагами может способствовать формированию опухолевой стромы, необходимой для прогрессии опухоли.

\section{ЛИТЕРАТУРА}

1. Бережная Н. М., Чехун В. Ф. Иммунология злокачественного роста. - К.: Наукова думка, 2005. - 790 с.

2. Бережной А. Е., Гнучев Н. В., Георгиев Г. П. и др. Молекулярные механизмы взаимодействия опухоли иммунной системы // Вопросы онкологии. - 2008. T. 54 . - № 6 .

3. Билынский Б. Т., Володько Н. А., Шпарык Я. В. Иммунологические механизмы естественной противоопухолевой резистентности человека. - Львов, 1989. - 64 с.

4. Глузман Д. Ф., Абраменко И. В., Скляренко Л. М., Писнячевская Г. В. Иммуноцитохимическая диагностика злокачественных экссудатов. - К.: Наукова думка, 1993. - 104 c.

5. Осинский С. П., Глузмян Д. Ф., Клифф Й. и др. Молекулярная диагностика опухолей. - К.: ДИА, 2007. - 246 с.

6. Lin E. Y., Pollard I. W. Macrophages: modulators of breast cancer progression // Novartis. Found. Symp. - 2004. P.158-168.

7. Tsai N. M., Chen B. M., Wei S. L. et al. Anti-tumor immunoglobulin $\mathrm{M}$ increases lumg metastasis in an experimental model of malignant melanoma // Clin. Exp. Metastasis. 2003. - v. 20. - № 2. - P. 103-109.

Поступила 30.05.2012

Рецензент д. м. н. С. И. Полякова

\title{
PECULIARITIES OF INTERACTION OF THE MELANOMA CELLS WITH MACROPHAGES OF THE PERIPHERAL BLOOD OF PATIENTS WITH UVEAL MELANOMA IN DIFFERENT CLINICAL COURSE OF THE TUMOR PROCESS
}

\author{
Velichko L. N., Vit V. V. \\ Odessa, Ukraine
}

There were studied peculiarities of interaction of the melanoma cells with macrophages of the peripheral blood in 22 patients with uveal melanoma. The study of macrophage- tumor rosette formation and degree of the cytotoxic damage of tumor cells by macrophages was carried out in patients with different effectiveness of the combined therapy. The patients with uveal melanoma with metastases were noted to have a reliable increase in the level of macrophage- tumor rosette formation and absence of the cytotoxic damage of the tumor cells in comparison with the group of patients with the tumor regression. In the tumor regression interaction of the melanoma cells with the macrophages leads to the cytotoxic damage of the latter. 